\title{
ANALISIS NILAI TAMBAH PRODUK AGROINDUSTRI PERMEN SUSU DI KECAMATAN MOYO UTARA KABUPATEN SUMBAWA
}

\section{ANALYSIS OF THE VALUE ADDED OF MILK CANDY AGROINDUSTRY PRODUCT IN THE NORTHERN MOYO DISTRICT SUMBAWA REGENCY}

\author{
Try Wasjud Waqtarib ${ }^{1^{*}}$, Taslim Sjah $^{2}$, L. Sukardi ${ }^{2}$ \\ ${ }^{1}$ Program Studi Agribisnis Fakultas Pertanian Universitas Mataram, Mataram, Indonesia \\ ${ }^{2}$ Program Studi Agribisnis Fakultas Pertanian Universitas Mataram, Mataram, Indonesia \\ *Email Penulis korespondensi: trywasjud@gmail.com
}

\begin{abstract}
Abstrak
Tujuan dari penelitian ini adalah (1) Untuk menganalisis nilai tambah produk agroindustri permen susu di Kecamatan Moyo Utara Kabupaten Sumbawa (2) Untuk menganalisis keuntungan produk agroindustri permen susu di Kecamatan Moyo Utara Kabupaten Sumbawa (3) Untuk mengidentifikasi hambatan yang dihadapi usaha agroindustri permen susu di Kecamatan Moyo Utara Kabupaten Sumbawa. Metode yang digunakan dalam penelitian ini adalah metode deskriptif. Penelitian ini dilakukan di Kecamatan Moyo Utara Kabupaten Sumbawa. Kecamatan Moyo Utara terdiri atas 6 Desa yaitu, Desa Baru Tahan, Desa Kukin, Desa Penyaring, Desa Pungkit, Desa Sebewe dan Desa Songkar. Dari keenam desa tersebut ditetapkan Desa Penyaring sebagai daerah sampel penelitian secara (purposive sampling) atas pertimbangan bahwa terdapat usaha agroindustri permen susu di Desa Penyaring Kecamatan Moyo Utara Kabupen Sumbawa. Responden dalam penelitian dilakukan secara sensus artinya semua pengusaha agroindustri yang ada dan masih aktif di Desa Penyaring Kecamatan Moyo Utara dijadikan sebagai responden. Analisis data yang digunakan dalam penelitian ini meliputi: Analisis Nilai Tambah, Analisis Keuntungan, dan Analisis hambatan menggunakan Metode deskriptif. Hasil penelitian ini menunjukkan bahwa Rata-rata nilai tambah yang diperoleh responden agroindustri permen susu di Kecamatan Moyo Utara Kabupaten Sumbawa sebesar Rp 16.445/liter dengan rasio nilai tambah sebesar 41,52\%. Rata-rata keuntungan pada usaha agroindustri permen susu di Kecamatan Moyo Utara Kabupaten Sumbawa sebesar Rp 225.984/proses Produksi atau Rp 5.875.508/bulan. Hambatan yang dihadapi pengusaha agroindustri permen susu di Kecamatan Moyo Utara Kabupaten Sumbawa meliputi: (1) kontinuitas ketersediaan bahan baku (2) jangkauan pemasaran hasil produksi permen susu yang masih terbatas. Bagi pengusaha susu sapi segar yang ingin mendapatkan keuntungan yang maksimal, maka disarankan ketersediaan bahan baku agroindustri permen susu tersedia dengan cukup untuk memenuhi kebutuhan pengusaha permen susu.

Kata kunci: Nilai Tambah, Agroindustri, Permen Susu
\end{abstract}

\begin{abstract}
The objectives of this study are (1) To analyze the added value of a Milk Candy agroindustry business in North Moyo District, Sumbawa Regency (2) To analyze how much profit the Milk Candy agroindustry business is in the North Moyo District Sumbawa Regency (3) To identify the obstacles faced by the agroindustry business Milk Candy in North Moyo District, Sumbawa Regency. The method used in this research is descriptive method. This research was conducted in North Moyo District, Sumbawa Regency. North Moyo Subdistrict consists of 6 villages namely, Baru Tahan Village, Kukin Village, Penyaring Village, Pungkit Village, Sebewe Village and Songkar Village. Of the six villages, the Filter Village was designated as a research sample area (purposive sampling) based on the consideration that there was a milk candy agroindustry in the Filter Village, North Moyo District, Sumbawa Regency. Respondents in the study were conducted in a census meaning that all existing and still active agroindustry entrepreneurs in the Filter Village of North Moyo District were used as respondents. Analysis of the data used in this study includes: Value Added Analysis, Profit Analysis, and Obstacle Analysis using descriptive methods. The results of this study indicate that the average value added obtained by milk candy agroindustry respondents in North Moyo Subdistrict, Sumbawa Regency is Rp. 16,445 / liter with an added value ratio of $41.52 \%$. The average profit on the milk candy agro-industry in North Moyo District, Sumbawa Regency is Rp 225,984 / Production process or Rp 5,875,508 / month. Obstacles faced by milk candy agro-industry entrepreneurs in North Moyo Subdistrict, Sumbawa Regency include: (1) continuity of raw material availability (2) limited marketing reach of milk candy production. For fresh
\end{abstract}


cow dairy entrepreneurs who want to get the maximum profit, it is recommended that the availability of raw milk candy agro-industry raw materials is sufficiently available to meet the needs of milk candy entrepreneurs.

Keywords: Value added, agro-industry, milk candy

\section{PENDAHULUAN}

Indonesia merupakan Negara agraris dan termasuk salah satu negara berkembang yang mengandalkan sektor pertanian sebagai sumber mata pencaharian dari mayoritas penduduknya, maupun sebagai penopang pembangunan (Husodo, 2008). Dalam rangka pembangunan pertanian, agroindustri merupakan penggerak utama perkembangan sektor pertanian, terlebih dalam masa yang akan datang posisi pertanian merupakan sektor andalan dalam pembangunan nasional sehingga peran agroindustri akan semakin besar (Udayana, 2011).

Khususnya di wilayah Kecamatan Moyo Utara, industri permen susu merupakan usaha mikro yang potensial dikembangkan di Kecamatan Moyo Utara. Permen susu merupakan produk andalan bagi masyarakat Kecamatan Moyo Utara karena dapat memberikan nilai tambah dari bahan baku susu sapi segar. Adapun jenis susu sapi yang digunakan untuk pembuatan permen susu yaitu susu sapi segar yang berasal dari perahan susu sapi hissar. Sapi hissar merupakan jenis sapi penghasil susu daerah tropis yang digunakan sebagai bahan baku utama pembuatan permen susu. (Syaifullah, 2014).

Oleh karena itu, perubahan bahan baku susu sapi segar menjadi produk permen susu harus dapat memberikan nilai tambah atau memberikan keuntungan. Permasalahannya adalah: (1) Berapa besar nilai tambah pada usaha agroindustri permen susu di Kecamatan Moyo Utara Kabupaten Sumbawa? (2) Berapa besar keuntungan pada usaha agroindustri permen susu di Kecamatan Moyo Utara Kabupaten Sumbawa? (3) Apa saja hambatan yang dihadapi pada usaha agroindustri permen susu di Kecamatan Moyo Utara Kabupaten Sumbawa?

Berdasarakan permasalahannya di atas, maka perlu dilakukan penelitian mengenai "Analisi Nilai Tambah Pada Usaha Agroindustri Permen Susu di Kecamatan Moyo Utara Kabupaten Sumbawa". Tujuan penelitian ini adalah: (1) Untuk menganalisis nilai tambah usaha agroindustri permen susu di Kecamatan Moyo Utara Kabupaten Sumbawa. (2) Untuk menganalisis keuntungan usaha agroindustri permen susu di Kecamatan Moyo Utara Kabupaten Sumbawa. (3) Untuk mengidentifikasi hambatan yang dihadapi pada agroindustri permen susu di Kecamatan Moyo Utara Kabupaten Sumbawa.

\section{METODE PENELITIAN}

Metode yang digunakan dalam penelitian ini adalah metode deskriptif yaitu metode yang bertujuan untuk memecahkan masalah yang terjadi pada waktu sekarang dengan cara mengumpulkan data, menyusun data, menganalisa data dan kemudian menarik kesimpulan (Nazir, 2009). Penelitian ini dilakukan di Kecamatan Moyo Utara Kabupaten Sumbawa. Kecamatan Moyo Utara terdiri atas 6 Desa yaitu, Desa Baru Tahan, Desa Kukin, Desa Penyaring, Desa Pungkit, Desa Sebewe dan Desa Songkar. Dari keenam desa tersebut ditetapkan Desa Penyaring sebagai daerah sampel penelitian secara (purposive sampling) atas pertimbangan bahwa terdapat usaha agroindustri permen susu di Desa Penyaring Kecamatan Moyo Utara Kabupen Sumbawa. Responden dalam penelitian ini adalah pengusaha agroindustri permen susu yang masih 
aktif di Kecamatan Moyo Utara Kabupaten Sumbawa, yaitu di Desa Penyaring sebanyak 10 unit agroindustri permen susu. Berdasarkan hal tersebut maka penelitian ini dilakukan dengan metode sensus artinya semua pengusaha agroindustri yang ada dan masih aktif di Desa Penyaring Kecamatan Moyo Utara dijadikan sebagai responden. Teknik yang digunakan untuk mengumpulkan data diantaranya yaitu wawancara dengan menggunakan kuesioner.

\section{Analisis Nilai Tambah}

Untuk menganalisis besarnya nilai tambah yang diperoleh dari usaha agroindustri permen susu dapat dihitung dengan menggunakan "Metode Hayami'" yang disajikan pada Tabel 1.

Tabel 1. Analisis Nilai Tambah dengan Metode Hayami

\begin{tabular}{|c|c|c|}
\hline No & Variabel & Nilai \\
\hline \multirow[t]{8}{*}{1.} & Output, Input dan Harga & \\
\hline & A. Output $(\mathrm{kg})$ & A \\
\hline & B. Input Bahan Baku (kg) & $\mathrm{B}$ \\
\hline & C. Tenaga Kerja (HKO) & $\mathrm{C}$ \\
\hline & D. Faktor Konversi & $\mathrm{D}=\mathrm{A} / \mathrm{B}$ \\
\hline & E. Koefesien Tenaga Kerja (HKO/ltr bb) & $\mathrm{E}=\mathrm{C} / \mathrm{B}$ \\
\hline & F. Harga Output Rata-Rata $(\mathrm{Rp} / \mathrm{kg})$ & $\mathrm{F}$ \\
\hline & G. Upah Rata-Rata Tenaga Kerja (Rp/HKO) & $\mathrm{G}$ \\
\hline \multirow[t]{10}{*}{2.} & Penerimaan dan Keuntungan & \\
\hline & H. Harga Bahan Baku (Rp/kg bb) & $\mathrm{H}$ \\
\hline & I. Sumbangan Input Lain $(\mathrm{Rp} / \mathrm{kg} \mathrm{bb})$ & I \\
\hline & J. Nilai Ouput $(\mathrm{Rp} / \mathrm{kg})$ & $\mathrm{J}=\mathrm{D} \times \mathrm{F}$ \\
\hline & K1. Nilai Tambah $(\mathrm{Rp} / \mathrm{kg})$ & $\mathrm{K} 1=\mathrm{J}-\mathrm{I}-\mathrm{H}$ \\
\hline & K2. Rasio Nilai Tambah (\%) & $\mathrm{K} 2=(\mathrm{K} 1 / \mathrm{J}) \times 100 \%$ \\
\hline & L1. Imbalan Tenaga Kerja (Rp/kg bb) & $\mathrm{L} 1=\mathrm{E} \times \mathrm{G}$ \\
\hline & L2. Rasio Bagian Tenaga Kerja (\%) & $\mathrm{L} 2=(\mathrm{L} 1 / \mathrm{K} 1) \times 100 \%$ \\
\hline & M1. Keuntungan (Rp/kg bb) & $\mathrm{M} 1=\mathrm{K} 1-\mathrm{L} 1$ \\
\hline & M2. Tingkat Keuntungan (\%) & $\mathrm{M} 2=(\mathrm{M} 1 / \mathrm{J}) \times 100 \%$ \\
\hline \multirow[t]{5}{*}{3.} & Balas Jasa Pemilik Faktor-Faktor Produksi & \\
\hline & N.Margin Keuntungan $(\mathrm{Rp} / \mathrm{kg})$ & $\mathrm{N}=\mathrm{J}-\mathrm{H}$ \\
\hline & N1. Pendapatan Tenaga Kerja (\%) & $\mathrm{N} 2=(\mathrm{L} 1 / \mathrm{N}) \times 100 \%$ \\
\hline & N2.Sumbangan Input Lain (\%) & $\mathrm{N} 3=(\mathrm{I} / \mathrm{N}) \times 100 \%$ \\
\hline & O. Keuntungan Kegiatan Produksi (\%) & $\mathrm{O}=(\mathrm{M} 1 / \mathrm{N}) \times 100 \%$ \\
\hline
\end{tabular}

Sumber: Said, G., 2005

\section{Analisis Keuntungan}

Untuk mengetahui besarnya keuntungan, secara matematis dapat dirumuskan sebagai berikut:

$$
\pi=\mathbf{T R}-\mathbf{T C}
$$

Keterangan:

$$
\begin{array}{ll}
\pi & =\text { Keuntungan } \\
\mathrm{TR} & =\text { Total penerimaan } \\
\mathrm{TC} & =\text { Total biaya }
\end{array}
$$




\section{Analisis Hambatan-hambatan yang dihadapi Produsen}

Untuk mengetahui hambatan-hambatan yang dihadapi oleh pelaku usaha agroindustri permen susu digunakan analisis deskriptif.

\section{HASIL DAN PEMBAHASAN}

\section{Karateristik Responden}

Karakteristik responden dalam penelitian ini yaitu pengelola permen susu meliputi umur, tingkat pendidikan, pengalaman berusaha, jumlah tanggungan. Untuk lebih jelasnya dapat dilihat pada Tabel 2 .

Tabel 2. Karakteristik Responden di Desa Penyaring Kecamatan Moyo Utara Kabupaten Sumbawa 2020.

\begin{tabular}{clcc}
\hline No & Uraian & Jumlah & persentase $(\%)$ \\
\hline 1 & Jumlah Responden (Orang) & 10 & 100 \\
2 & Umur (Tahun) & 7 & 70 \\
& $-\quad 38-45$ & 3 & 30 \\
& $-\quad 46-49$ & 10 & 100
\end{tabular}

3 Tingkat Pendidikan Responden

$\begin{array}{llcc}\text { - } & \text { Tamat Sekolah Menengah Pertama } & 1 & 10 \\ \text { - } & \text { Tamat Sekolah Menengah Atas } & 7 & 70 \\ \text { - } \quad \text { Tamat Sekolah Perguruan Tinggi (S1) } & 2 & 20 \\ \text { mlah } & 10 & 100\end{array}$

4 Jumlah Tanggungan Keluarga (Orang)

$\begin{array}{ccc}-1-2 & 3 & 30 \\ -\quad 3-4 & 3 & 30 \\ -\quad>5 & 4 & 40 \\ \text { umlah } & 10 & 100\end{array}$

$5 \quad$ Pengalaman Usaha (Tahun)

$\begin{array}{ccc}-9-14 & 8 & 80 \\ -\quad 15-19 & 2 & 20 \\ \text { Jumlah } & 10 & 100\end{array}$

Sumber : Data primer diolah (2020)

\section{Umur Responden}

Dalam analisis demografi, struktur umur penduduk dibedakan menjadi 3 kelompok yaitu: (1) kelompok umur muda dibawah 15 tahun; (2) kelompok umur produktif atau penduduk usia kerja 15-65 tahun dan (3) kelompok umur tua yaitu 65 tahun ke atas (Tjiptoherijanto, 2001). Umur berkaitan dengan kemampuan fisik dan produktivitas seseorang, makin lanjut umur seseorang akan semakin berkurang produktivitasnya. Umur dapat mempengaruhi kemampuan fisik dalam bekerja, cara berpikir serta keinginan untuk menerima ide-ide baru dalam mengelola usahanya. Sebaran umur responden dapat dilihat pada Tabel 2. 
Berdasarkan Tabel 2 dapat dilihat bahwa tingkat usia responden agroindustri permen susu yang berada pada kisaran usia 38-45 tahun sebanyak 7 orang dengan persentase $70 \%$. Hal ini menunjukkan bahwa responden yang ada di Desa Penyaring Kecamatan Moyo Utara Kabupaten Sumbawa menunjukkan bahwa usia responden agroindustri permen susu tergolong usia produktif, artinya baik secara fisik maupun mental mempunyai kemampuan untuk menghasilkan barang atau jasa dalam hal ini melakukan usaha agroindustri permen susu.

\section{Tingkat Pendidikan}

Berdasarkan Tabel 2 dapat diketahui pendidikan formal responden agroindustri permen susu di Kecamatan Moyo Utara sangat beragam. Mulai dari yang tingkat pendidikan sekolah menengah pertama hingga yang tamat perguruan tinggi. Tingkat pendidikan terbanyak yang ditempuh oleh pengusaha permen susu adalah tamatan SMA sebanyak 7 orang dengan persentase $70 \%$ dan yang paling rendah adalah tingkat pendidikan SMP dan tamatan Perguruan Tinggi. Hal ini menunjukkan pengusaha agroindustri permen susu di Kecamatan Moyo Utara rata-rata memiliki ilmu pengetahuan sehingga mudah dalam membaca dan menghitung rugi-laba dari kegiatan yang dilakukannya.

\section{Jumlah Tanggungan Keluarga}

Jumlah tanggungan akan mempengaruhi besar kecilnya biaya hidup yang harus ditanggung karena semakin banyak jumlah tanggungan anggota keluarga maka semakin besar pula beban yang dikeluarkan oleh rumah tangga tersebut. Berdasarkan Tabel 2 dapat diketahui bahwa jumlah tanggungan keluarga responden rumah tangga agroindustri permen susu yang terbanyak berada pada kisaran tanggungan sebanyak 5-6 orang dengan jumlah 4 orang dengan persentase $40 \%$. Hal ini bahwa keluarga agroindustri permen susu berada pada golongan keluarga besar sesuai dengan pendapat Ilyas (1998) yang menyatakan bahwa jumlah tanggungan keluarga yang berkisar antara 1-2 tergolong keluarga kecil sedangkan 3-4 tergolong keluarga menengah, dan jumlah tanggungan 5 orang atau lebih tergolong keluarga besar.

\section{Pengalaman Usaha}

Pengalaman usaha yang dimaksud dalam penelitian ini adalah lamanya pengusaha agroindustri dalam mengelola dan mengembangkan usahanya. Menurut Simanjuntak (1985) yang mengatakan bahwa pengalaman usaha dapat mempengaruhi pengetahuan dan keterampilan pengelola. Semakin lama pengalaman usahanya, maka akan terlihat keberhasilan suatu pengusaha dalam mengelola usahanya.

Berdasarkan Tabel 2 diketahui pengalaman usaha responden agroindustri permen susu pada kisaran 9-19 tahun. Jumlah responden memiliki pengalaman berusaha sekitar 9-14 tahun yaitu sebanyak 8 orang dengan persentase 80\% dan 15-19 tahun sebanyak 2 orang dengan persentase $20 \%$. Hal ini menunjukkan bahwa responden telah memiliki pengalaman yang cukup dalam menjalankan usahanya.

\section{Nilai Tambah Agroindustri Permen Susu}

Analisis nilai tambah digunakan untuk mengetahui besarnya tambahan nilai yang terdapat pada susu sapi segar yang diolah menjadi permen susu. Untuk mengetahui besarnya nilai tambah pada agroindustri permen susu digunakan analisis nilai tambah dengan menggunakan "Metode Hayami". Dalam penelitian ini, peneliti hanya menganalisis nilai tambah permen susu.

Tabel 3. Analisis Nilai Tambah Produk Agroindustri Permen Susu di Kecamatan Moyo Utara Kabupaten Sumbawa Tahun 2020.

\begin{tabular}{lcc} 
No & Variabel & Nilai \\
\hline
\end{tabular}




\begin{tabular}{cllr}
\hline 1 & Output (kg) & $\mathrm{A}$ & 5,10 \\
2 & Bahan Baku (kg) & $\mathrm{B}$ & 15,30 \\
3 & Tenaga Kerja (HKO) & $\mathrm{C}$ & 2,20 \\
4 & Faktor Konversi & $\mathrm{D}=\mathrm{A} / \mathrm{B}$ & 0,33 \\
5 & Koefisien Tenaga Kerja (HKO/kg bb) & $\mathrm{E}=\mathrm{C} / \mathrm{B}$ & 0,14 \\
6 & Harga Output rata - rata (Rp/kg) & $\mathrm{F}$ & 120.000 \\
7 & Upah rata - rata Tenaga Kerja (Rp/HKO) & $\mathrm{G}$ & 30.000 \\
\hline \multicolumn{4}{c}{ Penerimaan dan Keuntungan } \\
\hline 8 & Harga Bahan Baku (Rp/kg bb) & $\mathrm{H}$ & 17.500 \\
9 & Sumbangan Input Lain (Rp/kg bb) & $\mathrm{I}$ & 5.655 \\
10 & Nilai Output (Rp/kg) & $\mathrm{J}=\mathrm{D} \times \mathrm{F}$ & 39.600 \\
11 & a. Nilai Tambah (Rp/kg bb) & $\mathrm{K}=\mathrm{J}-\mathrm{I}-\mathrm{H}$ & 16.445 \\
& b. Rasio Nilai Tambah (\%) & $\mathrm{L}=(\mathrm{K} / \mathrm{J}) \times 100 \%$ & 41,52 \\
12 & a. Imbalan Tenaga Kerja (Rp/HKO) & $\mathrm{M}=\mathrm{E} \times \mathrm{G}$ & 4.200 \\
& b. Rasio Bagian Tenaga Kerja & $\mathrm{N} \%=(\mathrm{M} / \mathrm{K}) \times 100 \%$ & 25,53 \\
13 & a. Keuntungan (Rp/kg bb) & $\mathrm{O}=\mathrm{K}-\mathrm{M}$ & 12.245 \\
& b. Tingkat Keuntungan (\%) & $\mathrm{P}=(\mathrm{O} / \mathrm{K}) \times 100 \%$ & 74,46 \\
\hline \multicolumn{4}{c}{ Balas jasa pemilik faktor-faktor produksi } \\
\hline 14 & Margin Keuntungan & $\mathrm{Q}=\mathrm{J}-\mathrm{H}$ & 22.100 \\
& a. Keuntungan Perusahaan (\%) & $\mathrm{R}=(\mathrm{O} / \mathrm{Q}) \times 100 \%$ & 19,00 \\
& b. Pendapatan Tenaga Kerja (\%) & $\mathrm{S}=(\mathrm{M} / \mathrm{Q}) \times 100 \%$ & 25,58 \\
& c. Sumbangan Input Lain (\%) & $\mathrm{T}=(\mathrm{I} / \mathrm{Q}) \times 100 \%$ & 55,40 \\
\hline
\end{tabular}

Sumber: Data primer diolah (2020)

Berdasarkan Tabel 3 menggambarkan nilai tambah per kilogram bahan baku susu sapi segar produk agroindustri permen susu di Kecamatan Moyo Utara Kabupaten Sumbawa tahun 2020 adalah sebesar Rp 16.445/kg bahan baku dengan rasio nilai tambah sebesar $41,52 \%$. Ini berarti untuk setiap satu liter susu sapi segar yang digunakan dalam proses produksi dapat memberikan nilai tambah 41,52\%. Hal ini disebabkan nilai tambah ditentukan oleh kemampuan bahan baku dalam memproduksi permen susu dan harga jual produk.

\section{Biaya Produksi Agroindustri Permen Susu}

Dalam agroindustri permen susu biaya produksi meliputi biaya variabel dan biaya tetap. Biaya variabel meliputi biaya bahan baku, biaya bahan penolong, biaya tenaga kerja dan biaya lain-lain (biaya transportasi) sedangkan biaya tetap meliputi biaya penyusutan alat. Biaya bahan baku dalam penelitian ini adalah biaya yang dikeluarkan untuk memperoleh bahan baku untuk proses produksi permen susu. Biaya bahan penolong meliputi biaya yang dikeluarkan untuk memperoleh bahan pendukung dalam proses produksi permen susu, Biaya tenaga kerja adalah biaya yang dikeluarkan untuk mengupah tenaga kerja, Biaya lain-lain yang dihitung adalah perkiraan biaya dalam kegiatan agroindustri seperti biaya transportasi. Sedangkan biaya penyusutan dalam penelitian ini adalah penyusutan alat yang digunakan dalam agroindustri permen susu.

Untuk lebih jelasnya rata-rata biaya produksi agroindustri permen susu di Kecamatan Moyo Utara Kabupaten Sumbawa 2020 disajikan pada Tabel 4 berikut: 
Tabel 4 Rata-Rata Biaya Produksi Per Proses Produk Agroindustri Permen Susu Kecamatan Moyo Utara Kabupaten Sumbawa 2020.

\begin{tabular}{llrr} 
No & Jenis Biaya Produksi & Nilai (Rp) & Persentase (\%) \\
\hline 1 & Biaya Variabel & & \\
& a. Biaya Bahan Baku & 269.100 & 69,71 \\
& b. Biaya Bahan Penolong & 76.765 & 19,89 \\
& c. Biaya Tenaga Kerja & 30.000 & 7,77 \\
& Total Biaya Variabel & 375.865 & \\
2 Biaya Tetap & & 0,04 \\
& a. Biaya Penyusutan Alat & 154 & 2,59 \\
Biaya Lain-lain & & 100,00 \\
\hline & (Transportasi) & 386.019 & \\
\hline
\end{tabular}

Sumber: Data primer diolah (2020)

Dari Tabel 4 tampak bahwa jumlah biaya produksi terbesar yang dikeluarkan pada agroindustri permen susu di Kecamatan Moyo Utara Kabupaten Sumbawa terdapat pada biaya bahan baku yaitu sebesar Rp 269.100 per satu kali proses produksi dengan persentase $69,71 \%$. Sehingga secara keseluruhan jumlah biaya produksi pada agroindustri permen susu adalah sebesar Rp 386.019. Berdasarkan hasil penelitian diketahui jumlah rata-rata kebutuhan bahan baku produk agroindustri permen susu di Kecamatan Moyo Utara Kabupaten Sumbawa dalam satu kali proses produksi sebanyak 15,3 kg susu sapi segar dengan harga Rp 17.500/kg susu sapi segar dengan total biaya bahan baku untuk permen susu adalah sebesar Rp 269.100. Biaya bahan penolong pada agroindustri permen susu adalah sebesar Rp 76.765 yang digunakan untuk membeli Gula, Minyak Tanah, Kertas Pembungkus dan bahan lainnya per proses produksi. Biaya tenaga kerja yang dimaksud dalam penelitian ini adalah upah yang diberikan oleh rumah tangga agroindustri permen susu kepada tenaga kerja. Tenaga kerja yang digunakan dalam agroindustri permen susu adalah tenaga kerja dalam keluarga (TKDK) dan tenaga kerja luar keluarga (TKLK) adalah sebesar Rp 30.000 per proses produksi.

Biaya tetap adalah biaya yang besar kecilnya tidak tergantung pada besar kecilnya produksi, dengan kata lain besar kecilnya biaya tidak mempengaruhi hasil produksi. Biaya tetap yang dimaksud dalam penelitian ini adalah biaya penyusutan alat. Berdasarkan hasil penelitian pada Tabel 4 tampak bahwa rata-rata biaya penyusutan alat yang dikeluarkan oleh responden rumah tangga agroindustri permen susu adalah sebesar Rp 154. Adapun alat yang digunakan pada agroindustri permen susu antara lain seperti, Kompor, Penggaris, Meja, Roll, Plastik Alas Meja, Pisau, Kain Lap, Pemalet, Sutil dan Wajan.

Biaya lain-lain adalah biaya yang dikeluarkan selain biaya bahan baku, biaya bahan penolong dan biaya tenaga kerja dimana biaya lain-lain yang dimaksud dalam penelitian ini yaitu biaya Transportasi. Berdasarakan Tabel 4 menunjukkan bahwa ratarata biaya lain-lain yang dikeluarkan oleh pengusaha agroindustri permen susu sebesar Rp 10.000 . 
Tabel 5 Rata-Rata Biaya Produksi Per Bulan Produk Agroindustri Permen Susu Kecamatan Moyo Utara Kabupaten Sumbawa 2020.

\begin{tabular}{llrr}
\hline No & Jenis Biaya Produksi & Nilai (Rp) & Persentase (\%) \\
\hline $1 \quad$ Biaya Variabel & & \\
& a. Biaya Bahan Baku & 6.996 .600 & 69,71 \\
& b. Biaya Bahan Penolong & 1.995 .890 & 19,89 \\
& c. Biaya Tenaga Kerja & 780.000 & 7,77 \\
& Total Biaya Variabel & 9.772 .490 & \\
$2 \quad$ Biaya Tetap & & 0,04 \\
& a. Biaya Penyusutan Alat & 4.002 & \\
Biaya Lain-lain & & 2,60 \\
\hline (Transportasi) & 260.000 & 100,00 \\
\hline
\end{tabular}

Sumber: Data primer diolah (2020)

Dari Tabel 5 tampak bahwa jumlah biaya produksi terbesar yang dikeluarkan produk agroindustri permen susu di Kecamatan Moyo Utara Kabupaten Sumbawa terdapat pada biaya bahan baku yaitu sebesar Rp 6.996 .600 per bulan produksi dengan persentase $69,71 \%$. Sehingga secara keseluruhan jumlah biaya produksi pada agroindustri permen susu adalah sebesar Rp 10.036.492. Berdasarkan hasil penelitian diketahui jumlah rata-rata kebutuhan bahan baku produk agroindustri permen susu di Kecamatan Moyo Utara Kabupaten Sumbawa dalam per bulan produksi sebanyak 398 $\mathrm{kg}$ susu sapi segar dengan harga $\mathrm{Rp} 17.500 / \mathrm{kg}$ susu sapi segar dengan total biaya bahan baku untuk permen susu adalah sebesar Rp 6.996.600/bulan. Biaya bahan penolong pada agroindustri permen susu adalah sebesar Rp 1.995.890/bulan yang digunakan untuk membeli Gula, Minyak Tanah, Kertas Pembungkus dan bahan lainnya per bulan produksi. Biaya tenaga kerja yang dimaksud dalam penelitian ini adalah upah yang diberikan oleh rumah tangga agroindustri permen susu kepada tenaga kerja. Tenaga kerja yang digunakan dalam agroindustri permen susu adalah tenaga kerja dalam keluarga (TKDK) dan tenaga kerja luar keluarga (TKLK) adalah sebesar Rp 780.000 per bulan produksi.

Biaya tetap adalah biaya yang besar kecilnya tidak tergantung pada besar kecilnya produksi, dengan kata lain besar kecilnya biaya tidak mempengaruhi hasil produksi. Biaya tetap yang dimaksud dalam penelitian ini adalah biaya penyusutan alat. Berdasarkan hasil penelitian pada Tabel 5 tampak bahwa rata-rata biaya penyusutan alat per bulan yang dikeluarkan oleh responden rumah tangga agroindustri permen susu adalah sebesar Rp 4.002. Adapun alat yang digunakan pada agroindustri permen susu antara lain seperti, Kompor, Penggaris, Meja, Roll, Plastik Alas Meja, Pisau, Kain Lap, Pemalet, Sutil dan Wajan. Biaya lain-lain adalah biaya yang dikeluarkan selain biaya bahan baku, biaya bahan penolong dan biaya tenaga kerja dimana biaya lain-lain yang dimaksud dalam penelitian ini yaitu biaya Transportasi. Berdasarakan Tabel 5 menunjukkan bahwa rata-rata biaya lain-lain yang dikeluarkan oleh pengusaha agroindustri permen susu sebesar Rp 260.000/bulan.

Keuntungan Usaha Agroindustri Permen Susu 
Keuntungan adalah selisih dari penerimaan dan pengeluaran dalam proses produksi. Sedangkan Jumlah Produksi yang dimaksud dalam penelitian ini adalah jumlah produksi yang dihasilkan agroindustri permen susu per proses produksi. Total penerimaan adalah hasil kali antara jumlah produksi agroindustri permen susu dengan harga jual produk agroindustri permen susu. Keuntungan produk agroindustri permen susu di Kecamatan Moyo Utara Kabupaten Sumbawa dapat dilihat pada Tabel 6 berikut: Tabel 6 Rata-rata Keuntungan Per Proses produk Agroindustri Permen Susu di

Kecamatan Moyo Utara Kabupaten Sumbawa 2020

\begin{tabular}{llr}
\hline No & Uraian & Jumlah \\
\hline 1 & Produksi (kg) & 5,1 \\
2 & Harga Jual (Rp/kg) & 120.000 \\
3 & Total Penerimaan (Rp) & 612.000 \\
4 & Total Biaya Produksi (Rp) & 386.016 \\
5 & Keuntungan (Rp) & 225.984 \\
\hline
\end{tabular}

Sumber: Data primer diolah (2020)

Berdasarkan Tabel 6 menunjukan keuntungan agroindustri permen susu adalah sebesar Rp 225.984/proses produksi, yang diperoleh dari selisih total penerimaan yaitu sebesar $\mathrm{Rp}$ 612.000/proses produksi dengan total biaya produksi yaitu sebesar Rp 386.016. Dengan rata-rata jumlah produksi sebesar 5,1/kg. Sedangkan untuk harga jual produk agroindustri permen susu di Kecamatan Moyo Utara Kabupaten Sumbawa dengan rata-rata sebesar Rp 120.000/kg sehingga didapat hasil sesuai dengan Tabel 6. Tabel 7 Rata-rata Keuntungan Per Bulan produk Agroindustri Permen Susu di

Kecamatan Moyo Utara Kabupaten Sumbawa 2020

\begin{tabular}{llr}
\hline No & Uraian & Jumlah \\
\hline 1 & Produksi $(\mathrm{kg})$ & 132,6 \\
2 & Harga Jual (Rp/kg) & 120.000 \\
3 & Total Penerimaan (Rp) & 15.912 .000 \\
4 & Total Biaya Produksi (Rp) & 10.036 .492 \\
5 & Keuntungan (Rp) & 5.875 .508 \\
\hline
\end{tabular}

Sumber: Data primer diolah (2020)

Berdasarkan Tabel 7 menunjukan keuntungan agroindustri permen susu adalah sebesar Rp 5.875.508/bulan produksi, yang diperoleh dari selisih total penerimaan yaitu sebesar Rp 15.912.000/bulan produksi dengan total biaya produksi yaitu sebesar Rp 10.036.492. Dengan rata-rata jumlah produksi sebesar 132,6/kg. Sedangkan untuk harga jual produk agroindustri permen susu di Kecamatan Moyo Utara Kabupaten Sumbawa dengan rata-rata sebesar Rp 120.000/kg sehingga didapat hasil sesuai dengan Tabel 4.7.

\section{Hambatan Yang Dihadapi Oleh Pengusaha Agroindustri Permen Susu}

Setelah dilakukan penelitian terhadap para pengusaha agroindustri permen susu di Kecamatan Moyo Utara Kabupaten Sumbawa maka didapatkan beberapa hambatan yang dihadapi oleh pengusaha permen susu dalam proses produksinya. Untuk lebih jelasnya mengenai rincian hambatan-hambatan yang dihadapi oleh pengusaha agroindustri permen susu di Kecamatan Moyo Utara Kabupaten Sumbawa disajikan pada Tabel 8 berikut ini.

Tabel. 8 Rincian Hambatan Yang Dihadapi Oleh Pengusaha Agroindustri Permen Susu di Kecamatan Moyo Utara Kabupaten Sumbawa.

No Hambatan-hambatan Yang Dihadapi Oleh Pengusaha Agroindustri Permen Susu 


\begin{tabular}{clcc}
\cline { 2 - 4 } & Hambatan-hambatan & Jumlah (orang) & Persentase (\%) \\
\hline 1 & Bahan baku & 6 & 60 \\
2 & Pemasaran hasil produksi & 4 & 40 \\
\hline
\end{tabular}

Sumber: Data primer diolah (2020)

Berdasarkan Tabel 8 menunjukkan bahwa terdapat beberapa hambatan hambatan yang dihadapi oleh pengusaha agroindustri permen susu di Kecamatan Moyo Utara Kabupaten Sumbawa di antaranya adalah hambatan bahan baku (susu sapi segar) dan Pemasaran hasil produksi permen susu. Dari hasil penelitian dapat diketahui bahwa hambatan bahan baku merupakan hambatan yang paling banyak dialami oleh pengusaha permen susu yaitu sebanyak 6 responden dengan persentase $60 \%$ sedangkan hambatan pemasaran hasil produksi merupakan hambatan terendah yang dihadapi oleh pengusaha permen susu yaitu sebanyak 4 responden dengan persentase $40 \%$.

Setelah dilakukan penelitian terkait hambatan yang dihadapi pengusaha agroindustri permen susu di Kecamatan Moyo Utara Kabupaten Sumbawa maka diperlukan cara untuk mengatasi hambatan tersebut :

1. Kontinuitas ketersediaan bahan baku

Cara mengatasi: biasanya pengusaha mengatasi hambatan dengan cara membeli bahan baku susu sapi segar dalam bentuk banyak secara langsung kepeternak susu sapi dan membeli bahan baku susu sapi segar di luar daerah apabila peternak susu sapi tidak dapat memenuhi kebutuhan pengusaha permen susu.

2. Pemasaran hasil produksi

Cara mengatasi: menjalin kerja sama dengan pihak lembaga pemasaran di luar daerah dan memanfaatkan media sosial untuk menjaring konsumen dari semua kalangan secara efektif.

\section{KESIMPULAN DAN SARAN}

\section{Kesimpulan}

Berdasarkan hasil penelitian dan pembahasan, maka dapat ditarik kesimpulan sebagai berikut :

1. Nilai tambah yang diperoleh responden agroindustri permen susu di Kecamatan Moyo Utara Kabupaten Sumbawa sebesar Rp 16.445/kg bahan baku dengan rasio nilai tambah sebesar $41,52 \%$.

2. Keuntungan produk agroindustri permen susu di Kecamatan Moyo Utara Kabupaten Sumbawa sebesar Rp 225.984/proses Produksi atau Rp 5.875.508/bulan.

3. Hambatan yang dihadapi pengusaha agroindustri permen susu di Kecamatan Moyo Utara Kabupaten Sumbawa meliputi: (1) kontinuitas ketersediaan bahan baku (2) jangkauan pemasaran hasil produksi permen susu yang masih terbatas.

\section{Saran}

Berdasarkan hasil penelitian terkait dengan produk agroindustri permen susu di Kecamatan Moyo Utara Kabupaten Sumbawa, maka dapat disarankan bahwa:

1. Bagi pengusaha susu sapi segar yang ingin mendapatkan keuntungan yang maksimal, maka disarankan ketersediaan bahan baku agroindustri permen susu tersedia dengan cukup untuk memenuhi kebutuhan pengusaha permen susu.

2. Pengusaha agroindustri permen susu disarankan untuk menjalin kerja sama dan bermitra dengan pihak lembaga pemasaran diluar Kabupaten Sumbawa. Sehingga mampu mempromosikan dan menjual hasilnya dengan baik. 
3. Diharapkan kepada pemerintah Kabupaten Sumbawa agar dapat memfasilitasi koperasi usaha peternak susu sapi sehingga produsen tidak perlu membeli susu sapi dari luar daerah dan membantu pengusaha permen susu yang masih kurang maksimal dalam memasarkan hasil produksinya.

\section{DAFTAR PUSTAKA}

Hayami. (1987). Analisis Nilai Tambah dan Distribusi Kripik Nangka. Lembaga Penelitian Universitas Muhammadiyah Malang.

Husodo. (2008). Pertanian Mandiri: Pandangan Strategis Para Pakar Untuk Kemajuan Pertanian Indonesia. Penebar Swadaya: Jakarta.

Ilyas, S. (1998). Meningkatkan produksi nelayan tradisional. Jakarta.

Nazir M., (2009). Metode Penelitian. Cetakan Keempat. Ghalia Indonesia: Jakarta.

Syaifullah, (2014). Sapi HISSAR (Sapi Asli Sumbawa). Evoel. blogspot.co.id/ 2014/05/sapi-hissar-asli-sumbawa-html. (Diakses pada tgl 28 september 2019).

Tjiptoherijanto, P. (2001). Proyeksi Penduduk, Angkatan Kerja, Tenaga Kerja, dan Peran Serikat Pekerja dalam Peningkatan Kesejateraan. Majalah Perencanaan Pembangunan.

Udayana, I.G.B. (2011. Peran Agroindustri Dalam Pembangunan Pertanian. Singhadwala. 